\title{
Isolation of Vibrio Species on TSA Media and Comparision of Growth Percentage of Vibrio Species in Sea Water, Pond Water, Tap Water, Ground Water and River Water Samples
}

\author{
Pushpinder Paul ${ }^{1}$, Dr. Pawan Kumar ${ }^{2}$, Dr. Uma Shankar ${ }^{3}$ \\ ${ }^{1}$ Research Scholar, Department of Biotechnology, Singhania University, Rajasthan, India \\ ${ }^{2}$ Associate Professor, Department of Biotechnology, Singhania University, Rajasthan, India \\ ${ }^{3}$ Consultant Scientist at Cytogene Research and development, Lucknow, Uttar Pradesh, India
}

\begin{abstract}
The purpose of this study was to isolate the single colonies of Vibrio species from TCBS media to TSA media. After stereaking of single colonies on TSA media, petriplates were incubated for 24 hrs at $37^{\circ} \mathrm{C}$. After incubation period growth of Vibrio species on TSA plates were observed and also cross verify with TCBS plates. The entire samples showing same results in both (TCBS and TSA) media for Vibrio species. Identification of Vibrio species in different types of aquatic habitates (Sea water, River water, tap water, pond water and Ground water) and their percentage of growth was identified.
\end{abstract}

Keywords: Vibrio species, TSA, TCBS, Isolation etc.

\section{Introduction}

Vibrio is a genus of Gram-negative bacteria that possess a curved rod shape and naturally inhabits aquatic environments worldwide [1]. Within the genus Vibrio, several species are known to be important human pathogens.

Three species $V$. cholerae, V. parahaemolyticus, and $V$. vulnificus, are well-documented human pathogens [2] is a recognized pathogen with similar characteristics to $V$. cholerae, except an ability to ferment sucrose. Other species within the genus, such as $V$. alginolyticus, $V$. fluvialis , $V$. furnissii $V$. metschnikovii and $V$. hollisae are occasional human pathogens. Vibrio species account for a significant proportion of human infections from the consumption of raw or undercooked shellfish.

The genus Vibrio, within the family Vibrionaceae, is a diverse group of Gram-negative bacteria found exclusively in the aquatic environment. Important pathogenic members include Vibrio cholerae, the causative agent of cholera, and Vibrio parahaemolyticus and Vibrio vulnificus, which have been implicated in diarrhea, septicemia, and wound infections [3].

Vibrio species are gram-negative and largely halophilic. Although, depending on their sodium chloride requirements a few species are nonhalophilic also. Most of the species are also oxidase-positive. Most of them are sensitive to acidic $\mathrm{pH}$, while tolerant to alkaline $\mathrm{pH}$. As pathogenic organisms, the CDC estimates that there are 8,000 infections and 60 deaths each year that are the result of Vibrio infections (Centre for disease control) [4].

The Vibrio organisms are heterotrophic, obtaining nutrients from their mutualistic, parasitic, or pathogenic relationships with other organisms. Vibrio reproduces through asexual division. Many of the Vibrio species form relationships with animals. Some of them are mutualistic, as in the case of relationship between Vibrio and fish. $V$. fischeri is a well-known example for such type of relationships. One of the most interesting fact of the relationship between $V$. fischeri and its host (usually a squid) is that the host expells $90 \%$ of the $V$. fischeri each day [5].

Toxigenic Vibrio cholerae serogroup O141 has been associated with sporadic cholera-like diarrhea and bloodstream infection in the United States. Consumption of seafood and proximity to the coast may increase the risk of infection. All $V$. cholerae isolates recovered from stool samples of patients with diarrhea or from a normally sterile site should be serogrouped and assessed for cholera toxin production. Improved surveillance and case-control studies are needed to further characterize illness and risk factors for $V$. cholerae 0141 infection [6].

\section{Materials and Methods}

\subsection{Trypticase soy agar (TSA)}

Over development of green and yellow colonies on TCBS plates, single colonies were taken from TCBS media plate and streaked onto Trypticase Soy Agar (TSA) plates for obtaining discrete colonies after the incubation of $24 \mathrm{~h}$ at $37^{0} \mathrm{C}$. After incubation time all the plates were checked for confirmation of growth observed in TCBS media.

\section{Result and Discussion}

Collected total 30 water samples for presumptive and culturable 5 different Vibrio species (i.e., growing on TCBS specific media) from different area of Himachal Pradesh, Gujarat and Uttar Pradesh. Random colonies from TCBS plates were streaked on TSA media for confirmation of obtained results. 


\section{International Journal of Science and Research (IJSR)}

ISSN (Online): 2319-7064

Index Copernicus Value (2013): 6.14 | Impact Factor (2015): 6.391

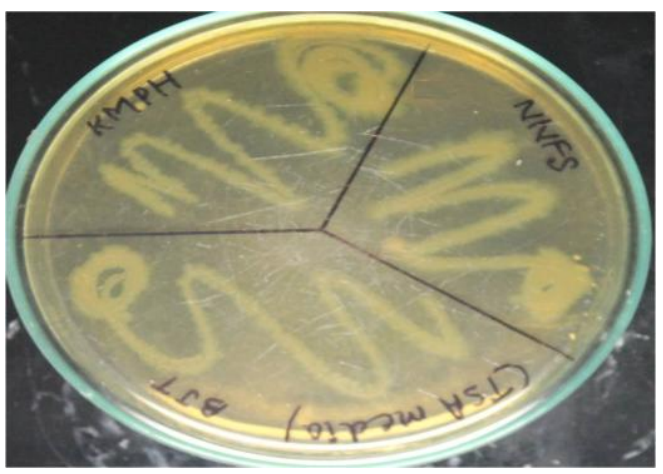

Figure 1: Locations: BJT, KMPH, NNFS

Colony taken for streaking: Green color

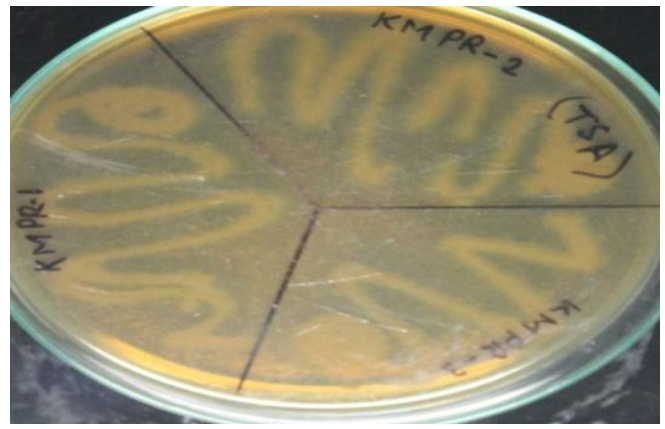

Figure 2: Locations: KMPR (1, 2, And 3)

Colony taken for streaking: Green \& Yellow color

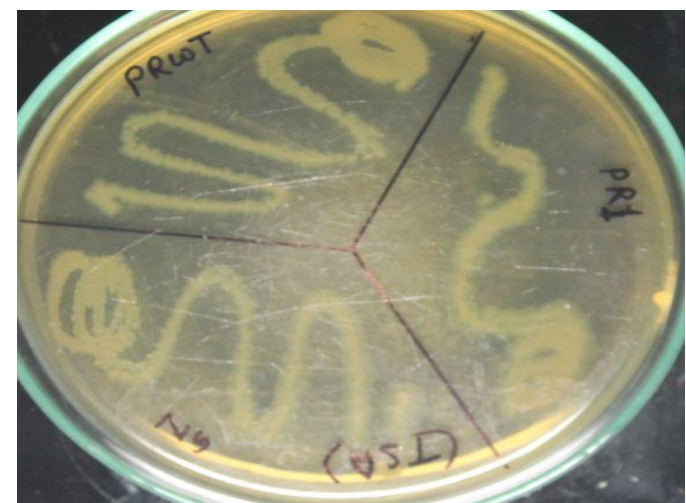

Figure 3 Locations: PR1, PRW, GN

Colony taken for streaking: Green color

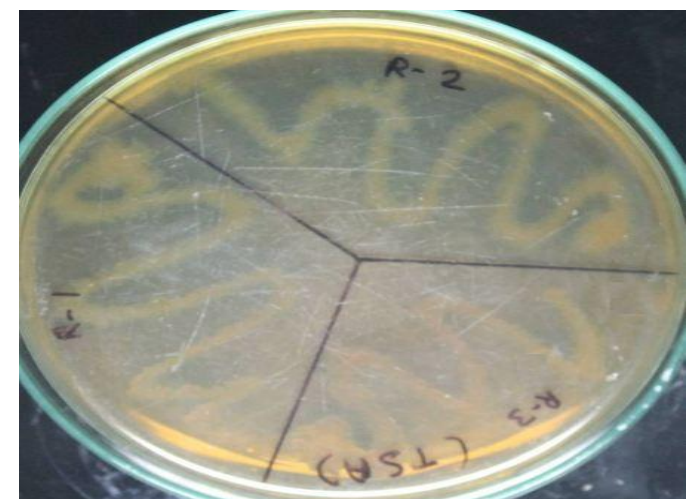

Figure 4: Locations: R (R1, R2, and R3)

Colony taken for streaking: Green color

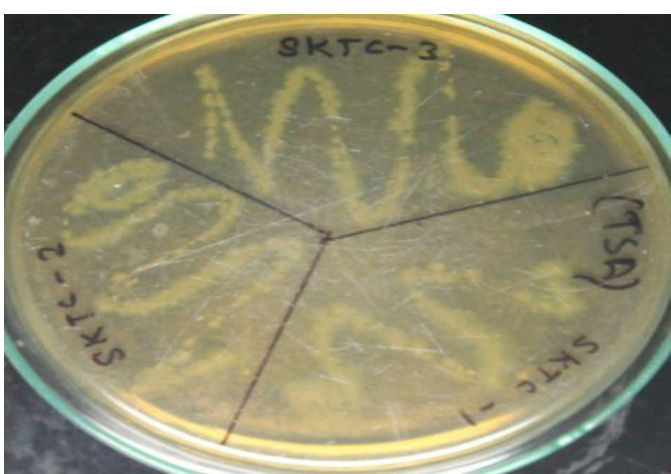

Figure 5: Locations: SKTC (1, 2 and 3)

Colony taken for streaking: Green color

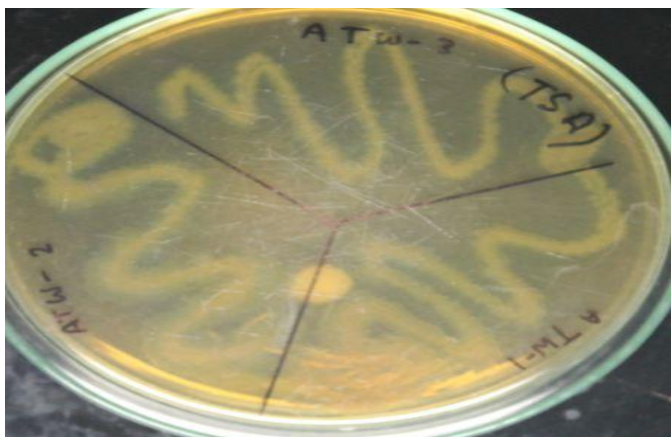

Figure 6: Locations: ATW (1, 2 and 3)

Colony taken for streaking: Green color

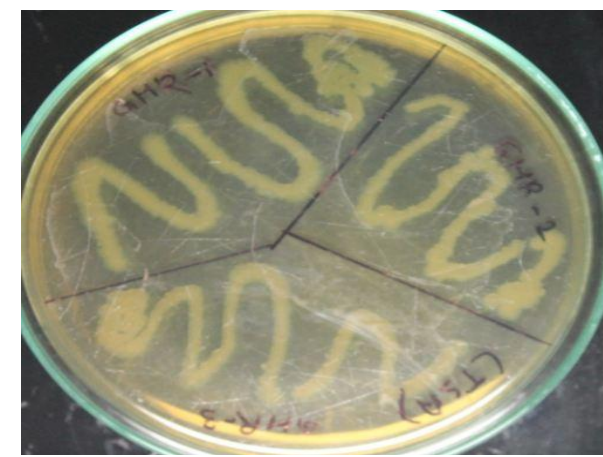

Figure 7: Locations: GHR (1, 2 and 3) Colony taken for streaking: Green color

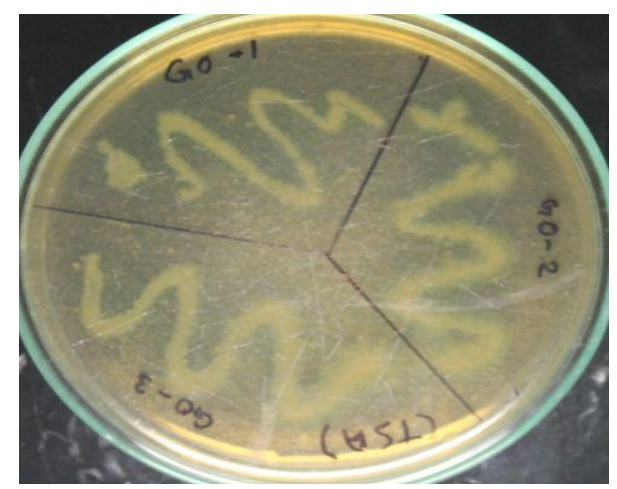

Figure 8: Locations: GO (1, 2 and 3) Colony taken for streaking: Yellow color 
International Journal of Science and Research (IJSR)

ISSN (Online): 2319-7064

Index Copernicus Value (2013): 6.14 | Impact Factor (2015): 6.391

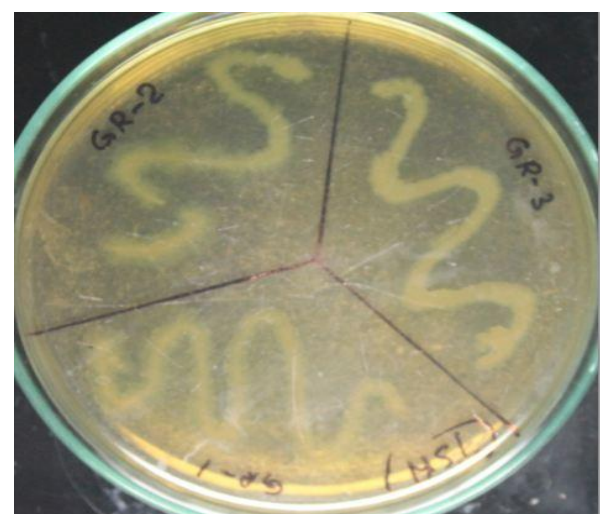

Figure 9: Locations: GR (1, 2 and 3) Colony taken for streaking: Yellow color

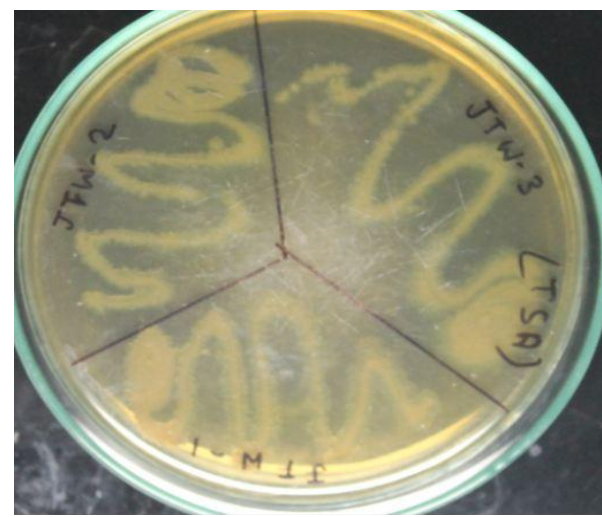

Figure 10: Locations: JTW (1, 2 and 3) Colony taken for streaking: Yellow color

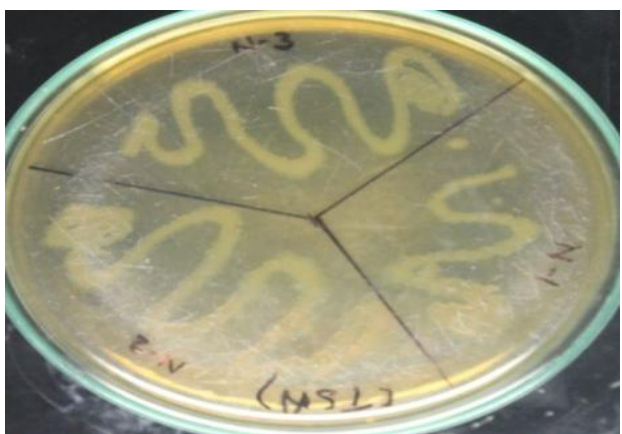

Figure 11: Locations: $\mathrm{N}(1,2$ and 3$)$ Colony taken for streaking: Green color

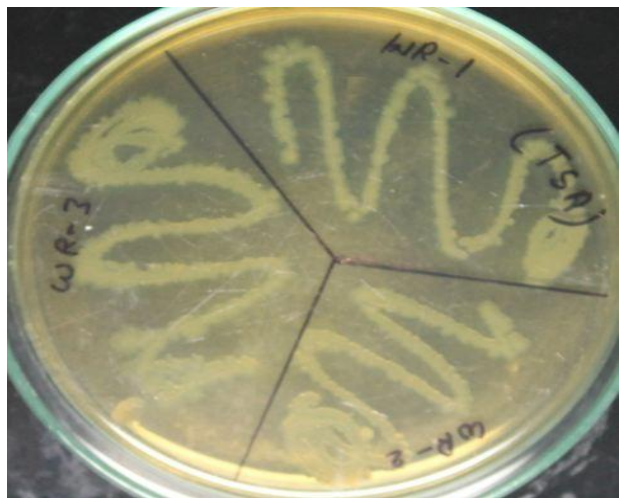

Figure 12: Locations: WR (1, 2 and 3) Colony taken for streaking: Green color

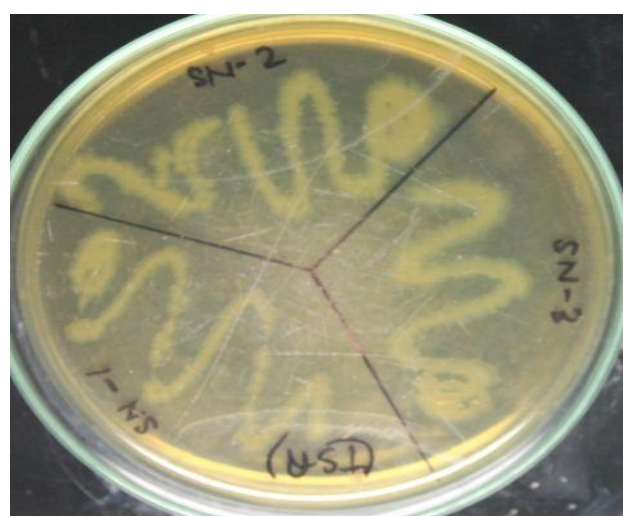

Figure 13: Locations: SN (1, 2 and 3) Colony taken for streaking: Green color

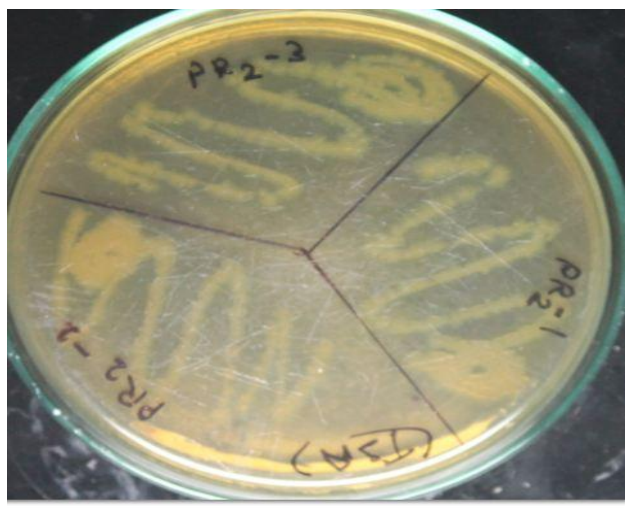

Figure 14: Locations: PR2 (1, 2 and 3) Colony taken for streaking: Green color

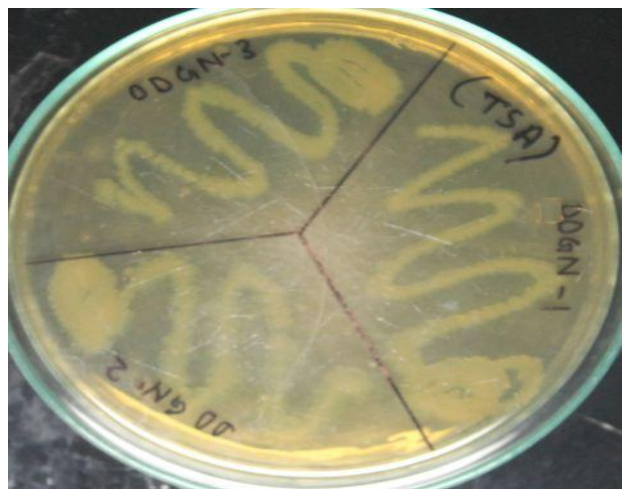

Figure 15: Locations: DDGN (1, 2 and 3) Colony taken for streaking: Green \& Yellow color

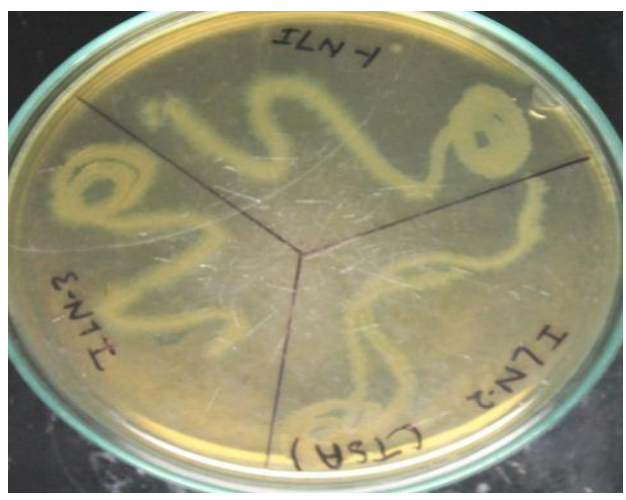

Figure 16: Locations: ILN (1, 2 and 3) Colony taken for streaking: Green color 


\section{International Journal of Science and Research (IJSR) \\ ISSN (Online): 2319-7064}

Index Copernicus Value (2013): 6.14 | Impact Factor (2015): 6.391

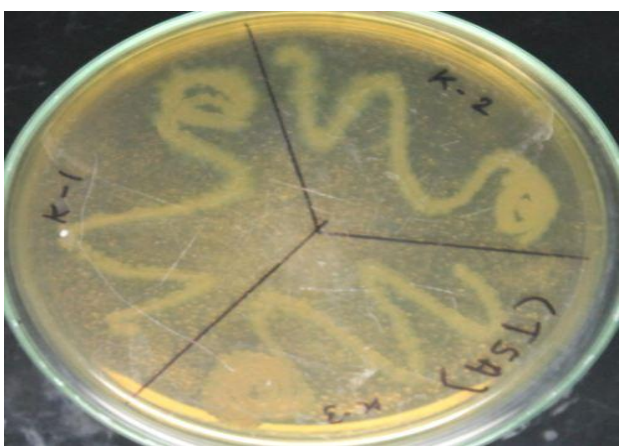

Figure 17: Locations: $\mathrm{K}$ (1, 2 and 3)

Colony taken for streaking: Green \& Yellow color

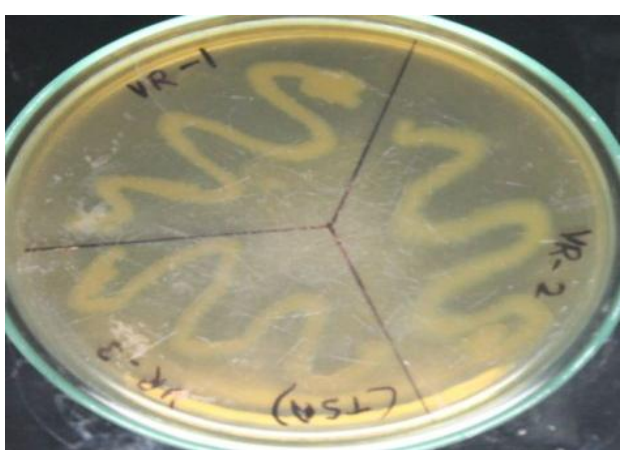

Figure 18: Locations: VR (1, 2 and 3$)$ Colony taken for streaking: Green Color

Table 1: Results of TCBS \& TSA

\begin{tabular}{|c|c|c|c|c|}
\hline S. No & Type of sample & Collection Place & TCBS Media & TSA Media \\
\hline 1 & Ground Water (Natural Resource) & Hamirpur (H.P) & + & + \\
\hline 2 & River Water & Hamirpur (H.P) & + & + \\
\hline 3 & Ground Water (Natural Resource) & Hamirpur (H.P) & + & + \\
\hline 4 & Ground Water (Natural Resource) & Hamirpur (H.P) & + & + \\
\hline 5 & River Water & Hamirpur (H.P) & + & + \\
\hline 6 & River Water & Hamirpur (H.P) & + & + \\
\hline 7 & River Water & Hamirpur (H.P) & + & + \\
\hline 8 & Ground Water (Natural Resource) & Hamirpur (H.P) & - & - \\
\hline 9 & River Water & Hamirpur (H.P) & + & + \\
\hline 10 & River Water & Hamirpur (H.P) & + & + \\
\hline 11 & Ground Water (Natural Resource) & Kangra (H.P) & + & + \\
\hline 12 & River Water & Hamirpur (H.P) & + & + \\
\hline 13 & Sea Water & Bharuch (Gujarat) & - & - \\
\hline 14 & Pond Water & Bharuch (Gujarat) & - & - \\
\hline 15 & River Water & Bharuch (Gujarat) & + & + \\
\hline 16 & River Water & Bharuch (Gujarat) & + & + \\
\hline 17 & Tap Water & Bharuch (Gujarat) & - & - \\
\hline 18 & Pond Water & Bharuch (Gujarat) & - & - \\
\hline 19 & Pond Water & Ankleshwar (Gujarat) & + & + \\
\hline 20 & River Water & Bharuch (Gujarat) & + & + \\
\hline 21 & Tap Water & Ajamgarh & + & + \\
\hline 22 & Tap Water & Jankipuram (Lucknow) & + & + \\
\hline 23 & River Water & Kanpur & + & + \\
\hline 24 & River Water & Gomti nagar (Lucknow) & + & + \\
\hline 25 & Tap Water & Lucknow & + & + \\
\hline 26 & Tap Water & Lucknow & + & + \\
\hline 27 & River Water & Lucknow & + & + \\
\hline 28 & Pond Water & PGI (Lucknow) & - & - \\
\hline 29 & Pond Water & Mohanlalganj (Lucknow) & - & - \\
\hline 30 & Pond Water & Telebagh (Lucknow) & - & - \\
\hline
\end{tabular}

From the above 30 sample results it shows that total 06 samples from pond water, 05samples from tap water, 01 samples from sea water, 05 samples from ground water(Natural resources) and 13 samples from river were collected for isolation and identification of Vibrio species. From 30 samples, some showing positive results and some showing negative results for Vibrio species with TCBS media.All the samples showing the same results while single colonies of Vibrio species were isolated from TCBS media and streaked on TSA media. It confirms the earlier results shown with TCBS media.

Out of 06 pond water sample, 01 no. shows positive results and 05 no. shows negative results.From tap water samples, 04 no. shows positive results and 01 no. shows negative results.From river water samples, all samples showing positive results for availability of Vibrio species.Sea water sample showing negative results for Vibrio specie. From ground water samples (Natural resource) 04 no. shows positive results and 01 no. shows negative results. The percentage of Vibrio species contamination in River water, Tap water and Ground water was found more than in Pond water and sea water. However variation observed in the results of water samples collcted from similar source but different location. Pond water sample collected from Gujarat showing some contamination of Vibrio species however pond water sample of Lucknow showing negative results.Similarly Tap water sample of Bharuch showing negative results of Vibrio species however Tap water sample of Lucknow showing positive resuts.However there was similarity found in all the results of river water collected from Gujarat, Lucknow and Himachal Pradesh locations. 


\section{International Journal of Science and Research (IJSR) \\ ISSN (Online): 2319-7064}

Index Copernicus Value (2013): 6.14 | Impact Factor (2015): 6.391

Table 2: \%age of Vibrio Species

\begin{tabular}{|c|c|c|c|c|c|c|}
\hline Water sample & Location of sample & Total samples & $+V e$ & $-V e$ & Percentage of Vibrio species & Overall Percentage of Vibrio species \\
\hline \multirow[b]{2}{*}{ Pond Water } & Bharuch (Gujarat) & 3 & 1 & 2 & $33.33 \%$ & \multirow[b]{2}{*}{$16.66 \%$} \\
\hline & $\begin{array}{c}\text { Lucknow } \\
\text { (UP) }\end{array}$ & 3 & 0 & 3 & $0 \%$ & \\
\hline \multirow[b]{2}{*}{ Tap Water } & Bharuch (Gujarat) & 1 & 0 & 1 & $0 \%$ & \multirow[b]{2}{*}{$80 \%$} \\
\hline & $\begin{array}{c}\text { Lucknow } \\
\text { (UP) }\end{array}$ & 4 & 4 & 0 & $100 \%$ & \\
\hline \multirow{3}{*}{ River Water } & Bharuch (Gujarat) & 3 & 3 & 0 & $100 \%$ & \multirow{3}{*}{$100 \%$} \\
\hline & $\begin{array}{c}\text { Lucknow } \\
\text { (UP) }\end{array}$ & 3 & 3 & 0 & $100 \%$ & \\
\hline & Himachal Pradesh & 7 & 7 & 0 & $100 \%$ & \\
\hline Sea Water & $\begin{array}{c}\text { Dahej } \\
\text { (Gujarat) }\end{array}$ & 1 & 0 & 1 & $0 \%$ & $0 \%$ \\
\hline Ground Water & Himachal Pradesh & 5 & 4 & 1 & $80 \%$ & $80 \%$ \\
\hline
\end{tabular}

\section{Conclusion}

From the above study it was clear that Vibrio species growth on TCBS media and TSA media was same.It was also found that sea water sample showing absence of Vibrio species however river water sample showing positive growth.Percentage of Vibrio contamination in River water, Tap water and Ground water was found much higher than Pond water and sea water.Also variation observed in the results of some water samples collcted from similar source but different location (Tap water and Pond water). However there was similarity found in all the results of river water collected from Gujarat, Lucknow and Himachal Pradesh locations.

\section{References}

[1] Blackwell, K.D. and Oliver, J.D. (2008). The ecology of Vibrio vulnificus, Vibrio cholerae, and Vibrio parahaemolyticus in North Carolina estuaries. $J$ Microbiol 46(2):146-53.

[2] McLaughlin, J.C (1995). Vibrio, p. 465-474. In P.R. Murray, E.J. Baron, M.A. Pfaller, F.C. Tenover, and R.H. Yolken (eds.), Manual of Clinical Microbiology, 6th ed. ASM Press, Washington.

[3] Farmer, J. J. I.,Janda, J. M., andBirkhead, K. M (2003). Vibrio, p. 706-718. In P. R. Murray (ed.), Manual of clinical microbiology, 8th ed. ASM Press, Washington, DC.

[4] Sujeewa, A. K. W., Norrakiah, A. S. and Laina, M (2000). Food Science Programme, School of Chemical Sciences and Food Technology,Faculty of Science and Technology, UniversitiKebangsaan Malaysia, 43600 Bangi, MalaysiaHealth and Food Quality Laboratory Selangor, Floor 1 and 2, Bangunan Hospital Lama, Jalan Pegawai, 41000, Klang, Selangor, Malaysia.

[5] CAC (2002).Discussion Paper on Risk Management Strategies for Vibrio spp. in Seafood. Food and Agriculture Organization / World Health Organization, Rome, Italy.

[6] John A. Crump, Cheryl A. Bopp, Katherine D. Greene, Kristy A. Kubota, Rebecca L. Middendorf, Joy G. Wells, and Eric D. Mintz (2003). Toxigenic Vibrio cholerae Serogroup O141-Associated CholeraLike Diarrhea and Bloodstream Infection in the United States. The Journal of Infectious Diseases, (187): 866868
Author Profile

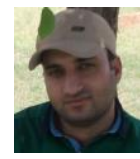

Pushpinder Paul received the M.Sc. degree in Biotechnolgy from Punjabi University, Patiala in 2008. From 2009 to till date he has worked with various pharmaceutical companies. His core area is sterile operations and validations. He is ISO 9001-2015 certified QMS Lead auditor from IRCA. He is $\mathrm{PhD}$ research scholar at Singhania University, Rajasthan. 